\title{
Optimization of fuzzy model using genetic algorithm for process control application
}

\begin{abstract}
A technique for the modeling of nonlinear control processes using fuzzy modeling approach based on the Takagiï Sugeno fuzzy model with a combination of genetic algorithm and recursive least square is proposed. This paper discusses the identification of the parameters at the antecedent and consequent parts of the fuzzy model. For the antecedent fuzzy parameters, genetic algorithm is used to tune them while at the consequent part, recursive least squares approach is used to identify the system parameters. This approach is applied to a process control rig with three subsystems: a heating element, a heat exchanger and a compartment tank. Experimental results show that the proposed approach provides better modeling when compared with Takagi Sugeno fuzzy modeling technique and the linear modeling approach.
\end{abstract}

Keyword: Fuzzy model; Genetic algorithm; Recursive least squares; Process control 